\title{
ABSORÇÃO DE NITROGÊNIO NATIVO DO SOLO PELO MILHO SOB PLANTIO DIRETO EM SUCESSÃO A PLANTAS DE COBERTURA ${ }^{(1)}$
}

\author{
Edson Cabral da Silva ${ }^{(2)}$, Takashi Muraoka ${ }^{(3)}$, Salatiér Buzetti ${ }^{(4)}$, \\ Marcos Emanuel da Costa Veloso ${ }^{(5)}$ \& Paulo César Ocheuze Trivelin ${ }^{(3)}$
}

\section{RESUMO}

O não revolvimento do solo com cultivo de adubos verdes na entressafra e o manejo da adubação nitrogenada alteram, geralmente, a dinâmica e a recuperação do $\mathrm{N}$ no sistema solo-planta. O objetivo deste trabalho foi avaliar a quantidade de $\mathrm{N}$ nativo do solo absorvido pelo milho em plantio direto, sob diferentes doses de $\mathrm{N}$, em sucessão à crotalária (Crotalaria juncea), ao milheto (Pennisetum americanum) e à vegetação espontânea (pousio) em um Latossolo Vermelho no Cerrado. O estudo foi desenvolvido na fazenda experimental da Faculdade de Engenharia de Ilha Solteira-UNESP, Selvíria-MS, nos anos agrícolas 2001/02 e 2002/03. O delineamento experimental foi o de blocos casualizados com 15 tratamentos e quatro repetições, dispostos em esquema fatorial, $5 \times 3$, sendo cinco doses de $\mathrm{N}$, na forma de uréia ( 0 , $30,80,130$ e $180 \mathrm{~kg} \mathrm{ha}^{-1}$ ) e três sistemas de cobertura do solo (crotalária, milheto e o solo em pousio na entressafra). A quantidade de $\mathrm{N}$ nativo do solo absorvida pelo milho foi calculada pela diferença entre total de $\mathrm{N}$ acumulado na planta de milho, na época da maturação fisiológica, e o somatório do $\mathrm{N}$ proveniente da uréia, do milheto ou da crotalária determinados pelo método isotópico com ${ }^{15} \mathrm{~N}$. O solo forneceu a maior quantidade de $\mathrm{N}$ para o milho, comparada à do fertilizante inorgânico conjuntamente à dos adubos verdes. As doses de $\mathrm{N}$ e os sistemas de cobertura do solo influenciaram significativamente a absorção de $\mathrm{N}$ nativo do solo pelo milho.

Termos de indexação: Zea mays, mineralização, fertilizante 15N, pousio, adubo verde, matéria orgânica do solo.

\footnotetext{
(1) Extraído da Tese de Doutorado do primeiro autor apresentada ao Programa de Pós-Graduação em Ciências do Centro de Energia Nuclear na Agricultura - CENA/USP. Recebido para publicação em julho de 2005 e aprovado em junho de 2006.

(2) Engenheiro-Agrônomo, Pós-doutorando do CENA/USP. Rua do Trabalho, 578, Apto. 1, Vila Independência, CEP 13418-220, Piracicaba, SP. Bolsista da FAPESP. E-mail: ecsilva@cena.usp.br

(3) Professor Associado do CENA/USP. Bolsistas do CNPq. E-mails: muraoka@cena.usp.br; pcotrive@cena.usp.br

(4) Professor Titular do Departamento de Solos e Engenharia Rural da FEIS/UNESP. Bolsista do CNPq. E-mail: sbuzetti@agr.feis.unesp.br

(5) Engenheiro-Agrônomo, Doutorando do Programa de Pós-Graduação em Irrigação e Drenagem da ESALQ/USP, E-mail: meveloso@esalq.usp.br
} 


\title{
SUMMARY: ABSORPTION OF SOIL NATIVE NITROGEN BY CORN UNDER NO-TILLAGE IN SUCCESSION TO COVER CROPS
}

\begin{abstract}
In untilled soils with green manure cultivation in during the dry season and the management of the nitrogen fertilization usually change the dynamics and the recovery of the nitrogen in the soil-plant system. The objective of this study was to evaluate the amount of native soil nitrogen absorbed by corn under no-tillage and submitted to different $N$ rates in succession to sunnhemp (Crotalaria juncea), millet (Pennisetum americanum) and fallow in a Red Latosol in the Cerrado. The experiment was carried out on an Experimental Farm of the Faculty of Engineering, Sao Paulo State University (UNESP-Ilha Solteira), which is situated in Selvíria, state of Mato Grosso do Sul, Brazil, during the 2001/02 and 2002/03 growing seasons. The experiment was set up in a randomized complete block design, with 15 treatments and four replications in a $5 \times 3$ factorial scheme, which consisted of the combination of five urea- $N$ rates $\left(0,30,80,130\right.$ and $180 \mathrm{~kg} \mathrm{ha}^{-1}$ of $\mathrm{N}$ ) and three preceding cover crops (sunnhemp, millet and fallow ground). The amount of soil native $N$ absorbed by corn was calculated by the difference between the total $N$ accumulated in the corn plant at physiologic maturation stage and the amount of $\mathrm{N}$ coming from urea, millet or sunnhemp as determined by the ${ }^{15} \mathrm{~N}$ isotopic method. The soil supplied greater $N$ amounts to corn than the inorganic fertilizer and green manures combined. The N rates and cover crop systems significantly influenced the uptake of soil native nitrogen by corn plants.
\end{abstract}

Index terms: Zea mays, mineralization, fertilizer ${ }^{15} \mathrm{~N}$, fallow, green manure, soil organic matter.

\section{INTRODUÇÃO}

Nas regiões tropicais e subtropicais, a diminuição do potencial produtivo dos solos agrícolas tem sido atribuída, principalmente, aos processos de erosão e decomposição da matéria orgânica do solo (Sá et al., 2001; Bayer et al., 2004). No sistema plantio direto (SPD), a deposição superficial dos resíduos vegetais e a não-incorporação desses ao solo contribuem para diminuição das perdas de matéria orgânica por erosão e mineralização microbiológica (Amado et al., 2002; Bayer et al., 2004). Esses fatores propiciam aumento nos teores de carbono orgânico, da CTC e de nutrientes no solo, especialmente de N (Corazza et al., 1999), constituindo o principal reservatório deste nutriente para as culturas em SPD, sobretudo para aquelas que não fixam $\mathrm{N}_{2}$ da atmosfera (Gonçalves et al., 2000; Amado et al., 2002).

O cultivo de adubos verdes na entressafra, sobretudo de leguminosas, antecedendo a cultura do milho em SPD, tem sido uma alternativa promissora na suplementação de N (Sá, 1996; Gonçalves et al., 2000; Amado et al., 2002). No entanto, pesquisas em que foi utilizado $\mathrm{N}$ marcado indicam que a maior proporção de $\mathrm{N}$ na biomassa de adubos verdes tem como destino o solo (Harris \& Hesterman, 1990; Scivittaro et al., 2003). A qualidade do resíduo vegetal, principalmente sua relação $\mathrm{C} / \mathrm{N}$, influencia diretamente a taxa de decomposição e imobilização/ mineralização do N (Muraoka et al., 2002) e, conseqüentemente, o aproveitamento do $\mathrm{N}$ destes resíduos, do $\mathrm{N}$ fertilizante e do $\mathrm{N}$ nativo do solo pelo milho (Lara Cabezas et al., 2004; Figueiredo et al., 2005).
Nas condições edafoclimáticas de Cerrado, as gramíneas têm sido mais utilizadas como plantas de cobertura, com destaque para o milheto, graças à sua maior resistência às deficiências hídricas com maior produção de biomassa (Lara Cabezas et al., 2004), menor custo das sementes e menor decomposição, comparado às leguminosas mesmo sob elevadas temperaturas associadas à alta umidade no verão (Sousa \& Lobato, 2004). Contudo, a maior parte das áreas cultivadas em SPD, principalmente as da região de Cerrado, permanece em pousio na entressafra, muitas vezes em razão do desconhecimento dos benefícios das plantas de coberturas para a manutenção do potencial produtivo do solo (Calegari, 2004).

O SPD, quando bem manejado, tem proporcionado produtividade de milho superior à de outros sistemas de cultivo, como o sistema convencional e cultivo mínimo (Fernandes et al., 1998). No entanto, há necessidade de mais estudos para o entendimento da dinâmica dos nutrientes nesse sistema de cultivo, principalmente do $\mathrm{N}$, por ser o nutriente exigido em maiores quantidades, por ser o principal responsável pelo aumento na produtividade da cultura de milho (Fernandes et al., 1998), além de ser o que, geralmente, mais onera o custo de produção (Vitti et al., 1999).

Normalmente, grande parte do $\mathrm{N}$ aplicado não é utilizada pela cultura do milho, ficando sujeita as possíveis perdas por erosão, lixiviação, desnitrificação e volatilização, bem como a grande interação que este nutriente sofre com o $\mathrm{N}$ do solo por processos de mineralização/imobilização (Lara Cabezas et al., 2000; Scivittaro et al., 2003). O uso de uma fonte marcada com ${ }^{15} \mathrm{~N}$ permite quantificar, com maior precisão, a 
eficiência deste nutriente (Scivittaro et al., 2000; Figueiredo et al., 2005), possibilitando também quantificar a contribuição do $\mathrm{N}$ nativo do solo (Rao et al., 1992; Muraoka et al., 2002), com vistas em facilitar a tomada de decisão quanto ao manejo do $\mathrm{N}$ e do solo e quanto à maior produtividade e preservação do meio ambiente.

O objetivo deste trabalho foi avaliar a quantidade de $\mathrm{N}$ nativo do solo absorvido pelo milho cultivado em plantio direto, sob diferentes doses de N, em sucessão à crotalária (Crotalaria juncea), ao milheto (Pennisetum americanum) e à vegetação espontânea (pousio) em um Latossolo Vermelho no Cerrado.

\section{MATERIAL E MÉTODOS}

O experimento foi realizado na fazenda experimental da Faculdade de Engenharia de Ilha Solteira UNESP, localizada no município de Selvíria, MS, cujas coordenadas geográficas são $51^{\circ} 22^{\prime} \mathrm{W}$ e $20^{\circ} 22^{\prime}$ 'S com $335 \mathrm{~m}$ de altitude, apresentando temperatura média anual de $24,5^{\circ} \mathrm{C}$, precipitação média anual de $1.370 \mathrm{~mm}$ e umidade relativa média de $64,8 \%$. O solo foi classificado como Latossolo Vermelho distroférrico (LVdf) fase cerrado tropical subcaducifólio (Embrapa, 1999).

O experimento foi realizado nos anos agrícolas 2001/02 e 2002/03, em áreas individuais com o mesmo histórico de uso e manejo, o qual apresentava 19 anos de preparo convencional do solo com cultivo de culturas anuais e os últimos cinco anos em SPD, área esta cultivada com arroz no último ano agrícola (2000/01). As análises químicas do solo realizadas antes da instalação do experimento, nas camadas de 0-0,10 e 0,10-0,20 m, resultaram, respectivamente, em $\mathrm{pH}$ $\left(\mathrm{CaCl}_{2}\right)$ 5,1 e 4,7; $\mathrm{N}$ total 0,9 e 0,8 $\mathrm{g} \mathrm{kg}^{-1} ; \mathrm{MO} 20,4 \mathrm{e}$ $17,7 \mathrm{~g} \mathrm{dm}^{-3}$; P (resina) 13,6 e 5,5 $\mathrm{mg} \mathrm{dm}^{-3}$; Ca 18,5 e $10,0 \mathrm{mmol}_{\mathrm{c}} \mathrm{dm}^{-3} ; \mathrm{Mg} 16,2$ e $7,2 \mathrm{mmol}_{\mathrm{c}} \mathrm{dm}^{-3} ; \mathrm{K} \mathrm{2,9} \mathrm{e}$ $1,3 \mathrm{mmol}_{\mathrm{c}} \mathrm{dm}^{-3} ; \mathrm{H}+\mathrm{Al} 23,3$ e 27,2 mmol $_{\mathrm{c}} \mathrm{dm}^{-3} ; \mathrm{S}$ 6,6 e $6,1 \mathrm{mg} \mathrm{dm}^{-3}$; SB 37,6 e 18,5 $\mathrm{mmol}_{\mathrm{c}} \mathrm{dm}^{-3}$; CTC 60,9 e $45,7 \mathrm{mmol}_{\mathrm{c}} \mathrm{dm}^{-3}$ e saturação por bases de $61,7 \mathrm{e}$ $40,5 \%$. As análises granulométricas, na camada de 0-0,20 m, resultaram num teor médio de 420,530 e $50 \mathrm{~g} \mathrm{~kg}^{-1}$ de areia, argila e silte, respectivamente.

O delineamento experimental foi o de blocos casualizados com 15 tratamentos e quatro repetições, dispostos em esquema fatorial $5 \times 3$, sendo cinco doses de $\mathrm{N}$, na forma de uréia $\left(0,30,80,130\right.$ e $\left.180 \mathrm{~kg} \mathrm{ha}^{-1}\right)$, aplicando-se $30 \mathrm{~kg} \mathrm{ha}^{-1}$ de ${ }^{15} \mathrm{~N}$ na semeadura e 50 , 100 e $150 \mathrm{~kg} \mathrm{ha}^{-1}$ de $^{15} \mathrm{~N}$ no estádio de quatro folhas e três sistemas de cobertura (crotalária e milheto marcados com ${ }^{15} \mathrm{~N}$ e o solo em pousio na entressafra). A vegetação espontânea do pousio constituiu-se predominantemente de capim-colonião e, em menor proporção, de trapoeraba, picão preto e corda-de-viola.

As parcelas foram constituídas de oito linhas de 0,80 $\mathrm{m}$ de largura com 7,0 $\mathrm{m}$ de comprimento, considerando-se, como área útil, as quatro linhas centrais, desprezando-se 1,0 m nas extremidades. As semeaduras da crotalária e do milheto foram realizadas com semeadora, respectivamente, em linhas espaçadas de 0,40 e $0,17 \mathrm{~m}$, em 17/9/2001 e 14/09/2002. A parte aérea das plantas não marcadas destas microparcelas foi substituída pelas plantas marcadas com ${ }^{15} \mathrm{~N}$, previamente fragmentadas com facão, tentando simular o triturador de palha (triton), que foi passado em toda a área do experimento em 30/11/01 e 26/11/ 02. Nos períodos de estiagem prolongada, foi feita irrigação suplementar por aspersão para as plantas de coberturas. A quantidade de $\mathrm{N}$ orgânico, na forma de resíduos vegetais, foi equivalente à aplicação no milho, respectivamente, em 2001 e 2002 , de 169 e $189 \mathrm{~kg} \mathrm{ha}^{-1}$ de N, para a crotalária, 68,5 e $64 \mathrm{~kg} \mathrm{ha}^{-1}$ de N, para o milheto, e 28,1 e 33,9 $\mathrm{kg} \mathrm{ha}^{-1}$ de N, para o pousio, considerando-se a produtividade de matéria seca (crotalária 9,77 e 8,60 t ha-1; milheto 7,37 e $6,33 \mathrm{t} \mathrm{ha}^{-1}$ e pousio 2,49 e $2,86 \mathrm{t} \mathrm{ha}^{-1}$, respectivamente, em 2001 e 2002).

As semeaduras do milho foram efetuadas mecanicamente em 05/12/2001 e 28/11/2002, utilizando-se um híbrido simples (Pioneer 30F80), de ciclo semiprecoce, na densidade de 65.000 sementes por hectare. A adubação de semeadura foi de $105 \mathrm{~kg} \mathrm{ha}^{-1}$ de $\mathrm{P}_{2} \mathrm{O}_{5}, 60 \mathrm{~kg} \mathrm{ha}^{-1}$ de $\mathrm{K}_{2} \mathrm{O}$ e $4 \mathrm{~kg} \mathrm{ha}^{-1}$ de $\mathrm{Zn}$, aplicada a $0,05 \mathrm{~m}$ abaixo e ao lado das sementes. A fonte de $\mathrm{N}$ utilizada, exceto nas microparcelas que receberam a uréia- ${ }^{15} \mathrm{~N}$, foi a uréia comercial $45 \%$ de $\mathrm{N}$, sendo esta aplicada manualmente em um sulco superficial a $0,20 \mathrm{~m}$ da linha da cultura do milho e coberta com uma camada de solo, numa tentativa de simular a aplicação mecanizada com implemento apropriado para cobertura nitrogenada incorporada no milho em SPD.

Os teores de $\mathrm{N}$ total e de carbono orgânico do solo foram analisados em amostras coletadas em quatro pontos da parcela, nas camadas de $0-0,10 ; 0,10-0,20$ e 0,20-0,40 m, com auxilio de enxadão, no centro da entrelinha, na época do florescimento do milho. As análises foram realizadas, conforme métodos descritos em Raij et al. (2001). Para a determinação da produtividade de matéria seca de parte aérea (palha) do milho, foram coletadas, por ocasião da maturação fisiológica, cinco plantas na área útil da parcela. A produtividade de grãos foi determinada por meio da coleta de espigas das quatro linhas centrais da área útil da parcela, sendo estas trilhadas e os dados transformados em $\mathrm{kg} \mathrm{ha}^{-1}$ de grãos, padronizados a $13 \%$ de umidade.

$\mathrm{O}$ enriquecimento isotópico em \% de átomos de ${ }^{15} \mathrm{~N}$ e o $\mathrm{N}$ total nos grãos e no restante da parte aérea (palha) foram determinados em espectrômetro de massa (IRMS), interfaceado com um analisador elementar de N no Laboratório de Isótopos Estáveis do CENA/USP, conforme método descrito em Barrie \& Prosser (1996). Para determinar a eficiência de utilização do $\mathrm{N}$ do fertilizante uréia, da crotalária ou 
do milheto marcados com ${ }^{15} \mathrm{~N}$, baseou-se no princípio da diluição isotópica, considerando o seu respectivo enriquecimento em $\%$ de átomos de ${ }^{15} \mathrm{~N}$, a quantidade de $\mathrm{N}$ aplicada como uréia ou adubo verde e a quantidade de ${ }^{15} \mathrm{~N}$ na planta de milho, descontando-se a variação natural do isótopo estável ${ }^{15} \mathrm{~N}$, que é de 0,366 \% (Barrie $\&$ Prosser, 1996). A quantidade de $\mathrm{N}$ nativo do solo no milho foi calculada mediante a diferença entre total de $\mathrm{N}$ acumulado na planta (palha + grãos) e quantidade de $\mathrm{N}$ proveniente do ${ }^{15} \mathrm{~N}$-uréia e do milheto ou da crotalária marcados com ${ }^{15} \mathrm{~N}$, utilizando-se a equação:

$$
\mathrm{QNPNS}=N A-Q N P P F-Q N P P A V
$$

em que QNPNS = quantidade de $\mathrm{N}$ na planta de milho (palha + grãos) nativo do solo $\left(\mathrm{kg} \mathrm{ha}^{-1}\right)$; $\mathrm{NA}=$ nitrogênio acumulado $\left(\mathrm{kg} \mathrm{ha}^{-1}\right) ; \mathrm{QNPPF}=$ quantidade de $\mathrm{N}\left(\mathrm{kg} \mathrm{ha}^{-1}\right)$ na planta de milho (palha + grãos) proveniente do fertilizante; e QNPPAV = quantidade de $\mathrm{N}\left(\mathrm{kg} \mathrm{ha}^{-1}\right)$ na planta de milho (palha + grãos) proveniente dos adubos verdes (milheto ou crotalária).

Para calcular a QNPNS sobre a vegetação espontânea (pousio), não foi considerado o $\mathrm{N}$ proveniente de sua matéria seca, pelo fato de não ter sido marcada com ${ }^{15} \mathrm{~N}$, considerando-se apenas o $\mathrm{N}$ acumulado subtraído da QNPPF.

Os dados foram submetidos à análise de variância, aplicando-se o teste $\mathrm{F}$, comparação de médias pelo teste de Tukey a 5 \% e análise de regressão.

\section{RESULTADOS E DISCUSSÃO}

\section{Carbono orgânico e $\mathrm{N}$ total no solo}

Os teores de carbono orgânico (Figura 1a) e de N total (Figura 1b) no solo, na época do florescimento do milho, em ambos os anos agrícolas, não apresentaram diferenças significativas entre as mesmas camadas avaliadas. Entretanto, diminuíram com a profundidade, fato esse já esperado, uma vez que o teor de $\mathrm{N}$ total do solo acompanha o teor de carbono orgânico, e, geralmente, diminui com a profundidade, principalmente no solo sob SPD, pelo fato de seu nãorevolvimento e a manutenção dos resíduos vegetais sobre sua superfície promoverem a formação de um gradiente entre as camadas superiores e as mais profundas (Corazza et al., 1999; Bayer et al., 2004).

O sistema de cultivo é um dos principais fatores que condiciona a velocidade de decomposição/ mineralização da matéria orgânica do solo e dos resíduos vegetais deixados pelas culturas, plantas de coberturas e, ou, pela vegetação espontânea (Amado et al., 2002). Todavia, o acréscimo do teor de carbono orgânico e de $\mathrm{N}$ total no solo somente ocorre ao longo dos anos (Gonçalves et al., 2000; Sá et al., 2001; Bayer et al., 2004). Nesse sentido, Bayer \& Mielniczuk (1997) observaram que a adoção de sistema de cultivos que promoveram o menor revolvimento do solo resultou, após cinco anos, em incremento do conteúdo de $\mathrm{N}$ total, sendo este, entretanto, restrito às camadas superficiais: de 0,0-0,025 e 0,025-0,075 m. Fernandes et al. (1998) também observaram aumento no teor de matéria orgânica do solo em SPD, após oito anos de cultivo, apenas na camada de $0,0-0,075 \mathrm{~m}$, atribuindo tal fato à maior atividade biológica nessa camada. Dessa forma, o fato de não ter havido diferença significativa entre as mesmas camadas no presente estudo deveu-se, provavelmente, ao relativo pouco tempo entre as amostragens (um ano). De maneira geral, as médias para os teores de $\mathrm{N}$ total no solo,
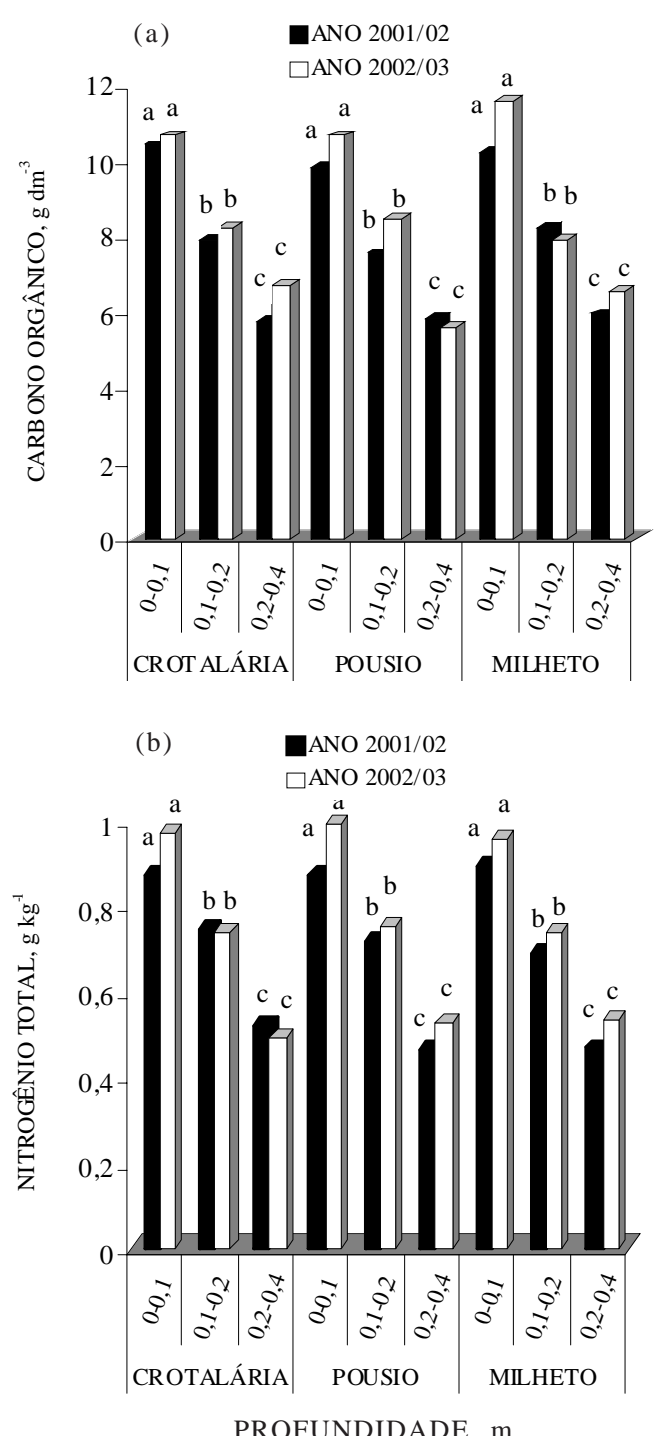

Figura 1. Teores de carbono orgânico (a) e de $\mathrm{N}$ total (b) no solo, nas camadas de $0-0,10 ; 0,10-0,20$ e 0,20-0,40 m, na época do florescimento do milho cultivado em sucessão à crotalária, milheto e ao solo em pousio, anos agrícolas 2001/02 e 2002/03. (Obs. médias seguidas por letras distintas na coluna diferem entre si pelo teste de Tukey a $5 \%)$. 
considerando o teor de matéria orgânica do solo em estudo, o qual apresentava como vegetação primária cerrado com menos de $20 \mathrm{~g} \mathrm{dm}^{-3}$ na camada de 0 $0,20 \mathrm{~m}$, ficaram dentro dos padrões considerados normais (Sousa \& Lobato, 2004).

\section{Produtividade do milho e acúmulo de nitrogênio nativo do solo}

As produtividades de grãos aumentaram de forma quadrática de acordo com as doses de $\mathrm{N}$ aplicadas, em ambos os anos agrícolas. No primeiro ano agrícola (Figura 2a), a máxima produtividade seria alcançada com as dose de 133, 142 e $170 \mathrm{~kg} \mathrm{ha}^{-1}$ de $\mathrm{N}$ no milho cultivado em sucessão à crotalária $\left(8.599 \mathrm{~kg} \mathrm{ha}^{-1}\right)$, pousio $\left(7.642 \mathrm{~kg} \mathrm{ha}^{-1}\right)$ e milheto $\left(7.569 \mathrm{~kg} \mathrm{ha}^{-1}\right)$, respectivamente. No segundo ano agrícola (Figura 2b), a máxima produtividade seria alcançada com as dose de 160, 173 e $172 \mathrm{~kg} \mathrm{ha}^{-1}$ de N, no milho cultivado em sucessão à crotalária $\left(8.966 \mathrm{~kg} \mathrm{ha}^{-1}\right)$, pousio $\left(7.991 \mathrm{~kg} \mathrm{ha}^{-1}\right)$ e milheto $\left(8.016 \mathrm{~kg} \mathrm{ha}^{-1}\right)$, respectivamente. $\mathrm{O}$ maior aporte de $\mathrm{N}$ pela crotalária favoreceu, provavelmente, o maior desenvolvimento do sistema radicular, levando ao maior aproveitamento do $\mathrm{N}$ e de outros nutrientes do solo (Jenkinson et al., 1985; Muraoka et al., 2002), e à maior mineralização do N do solo (Rao et al., 1992; Scivittaro et al., 2003), efeito conhecido como "priming". Esse efeito é relatado com mais freqüência na literatura em resposta à aplicação de fertilizantes minerais (Rao et al., 1992). No entanto, Scivittaro et al. (2000) e Muraoka et al. (2002) observaram o mesmo efeito, quando da aplicação de resíduos orgânicos ricos em $\mathrm{N}$.

Verificou-se que a quantidade de $\mathrm{N}$ na planta de milho (palha e grãos) nativo do solo (QNPNS) (Quadro 1), calculada pela diferença entre o total de $\mathrm{N}$ acumulado e o somatório do $\mathrm{N}$ proveniente do fertilizante ${ }^{15} \mathrm{~N}$-uréia (QNPPF) e dos adubos verdes milheto e crotalária marcados com ${ }^{15} \mathrm{~N}$ (QNPPAV) (Quadro 2), exceto para grãos no ano agrícola 2001/ 02, quanto aos sistemas de cobertura, e para a palha, quanto às doses de $\mathrm{N}$ no ano agrícola 2002/03, foi influenciada significativamente pelas doses e pelos sistemas de cobertura do solo. Houve também, em ambos os anos agrícolas, interação significativa entre doses de $\mathrm{N}$ e sistemas de cobertura, tanto para a QNPNS na palha quanto nos grãos, indicando que o N proveniente da uréia e dos adubos verdes influenciou a dinâmica e absorção do $\mathrm{N}$ nativo do solo pela planta. Tal fenômeno se deve, em parte, ao estímulo promovido pelo $\mathrm{N}$ mineral na atividade metabólica da planta (Scivittaro et al., 2000), pela influência que exerce no desenvolvimento do sistema radicular (Jenkinson et al., 1985) e na mineralização do $\mathrm{N}$ orgânico do solo (Rao et al., 1992; Muraoka et al., 2002; Scivittaro et al., 2003) e dos resíduos vegetais de culturas antecessoras (Lara Cabezas et al., 2004; Sousa \& Lobato, 2004).

De maneira geral, em qualquer sistema de manejo, ocorrem interações do $\mathrm{N}$ aplicado, seja de fontes orgânicas, seja inorgânicas, com o N orgânico do solo (Harris \& Hesterman, 1990; Powlson \& Barraclough, 1993), o qual, na maioria das vezes, caracteriza-se como a principal fonte de $\mathrm{N}$ para a cultura do milho (Amado et al., 2002; Figueiredo et al., 2005). No entanto, as distintas fontes de $\mathrm{N}$ e a conseqüente disponibilidade de $\mathrm{N}$ mineral na solução do solo sofrem grande interferência do sistema de cultivo utilizado, do esquema de rotação/sucessão de cultura utilizado (Gonçalves et al., 2000; Amado et al., 2002), da reação do solo (Vitti et al., 1999) e das condições edafoclimáticas (Lara Cabezas et al., 2004). Isto, em virtude de todos esses fatores influenciarem a atividade da microbiota do solo, mediadora dos processos de imobilização/mineralização do N.

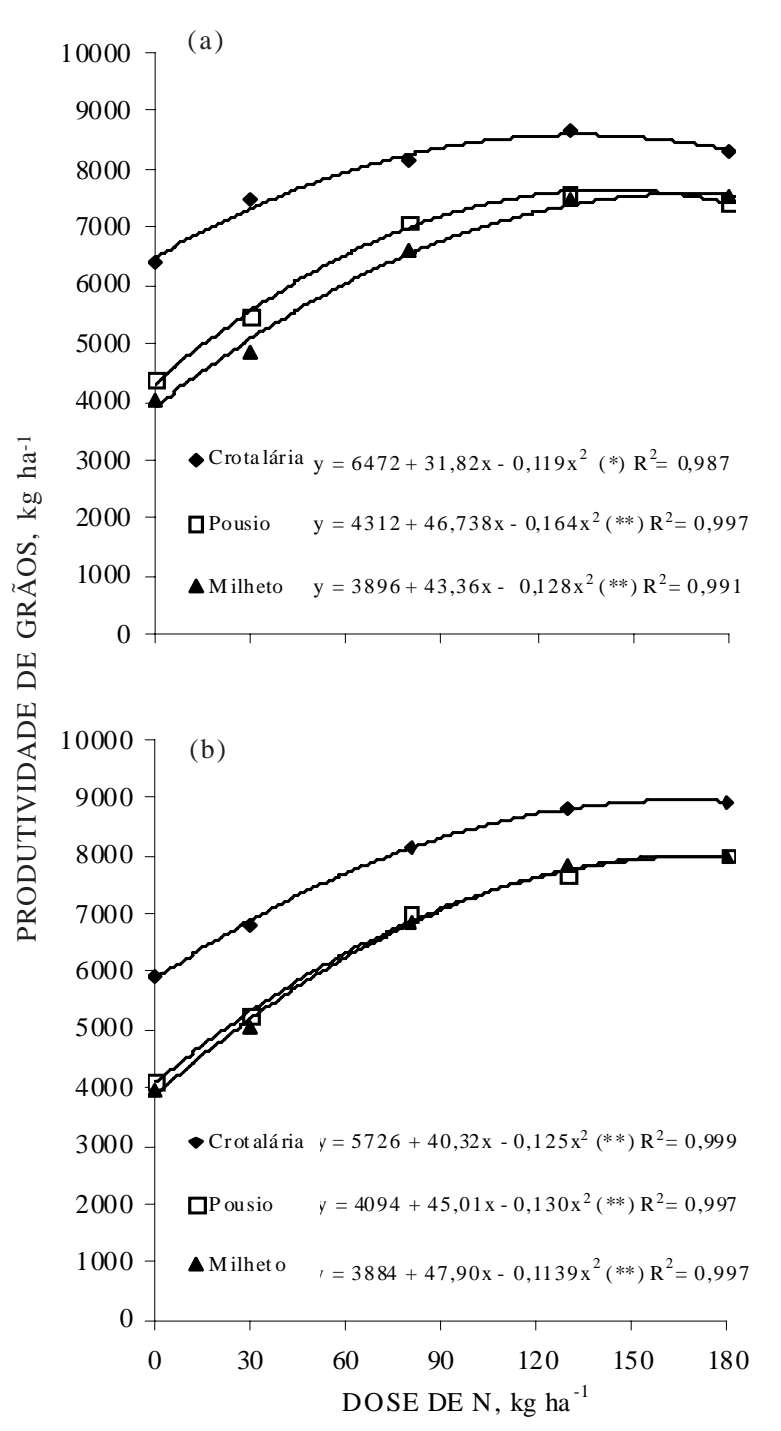

Figura 2. Produtividade de grãos de milho, considerando as doses de $\mathrm{N}$ e sistemas de cobertura do solo, anos agrícolas 2001/02 (a) e 2002/03 (b). (Obs. * e **: Significativos a 5 e $1 \%$ pelo teste $F$, respectivamente). 
Quadro 1. Valores de F da análise de variância e coeficientes de variação para a quantidade de N na planta de milho (palha e grãos) nativo do solo (QNPNS), considerando as doses de N e sistemas de cobertura do solo, anos agrícolas 2001/02 e 2002/03

\begin{tabular}{|c|c|c|c|c|}
\hline \multirow{2}{*}{ Variável } & \multicolumn{4}{|c|}{ QNPNS } \\
\hline & Palha & Grão & Palha & Grão \\
\hline & \multicolumn{2}{|c|}{$2001 / 02$} & \multicolumn{2}{|c|}{$2002 / 03$} \\
\hline Dose de N (D) & $8,14^{* *}$ & $9,37^{* *}$ & $0,67 \mathrm{~ns}$ & $41,82^{* *}$ \\
\hline Sistemas de cobertura (C) & $3,38^{*}$ & $1,17 \mathrm{~ns}$ & $4,40^{*}$ & $56,41^{* *}$ \\
\hline $\mathrm{DxC}$ & $6,34^{* *}$ & $4,73^{* *}$ & $3,90^{* *}$ & $6,18^{* *}$ \\
\hline Coeficiente de variação (\%) & 15,29 & 13,60 & 20,34 & 7,75 \\
\hline
\end{tabular}

$\mathrm{Ns},{ }^{*} \mathrm{e}^{* *}$ : não-significativo e significativos a 5 e $1 \%$ pelo teste $\mathrm{F}$, respectivamente.

Quadro 2. Quantidade de nitrogênio proveniente do fertilizante no milho (QNPPF) e dos adubos milheto e crotalária (QNPPAV), considerando as doses de N, anos agrícolas 2001/02 e 2002/03

\begin{tabular}{|c|c|c|c|c|c|c|c|}
\hline \multicolumn{2}{|c|}{ Dose de N } & \multicolumn{2}{|c|}{ Crotalária-milho } & \multicolumn{2}{|c|}{ Milheto-milho } & \multicolumn{2}{|c|}{ Pousio-milho } \\
\hline Semeadura & Cobertura & 2001/02 & $2002 / 03$ & 2001/02 & $2002 / 03$ & 2001/02 & $2002 / 03$ \\
\hline \multirow{8}{*}{$\begin{array}{l}30 \\
30 \\
30 \\
30\end{array}$} & & & & QNP & & & \\
\hline & 0 & 18,6 & 18,3 & 12,4 & 15,8 & 17,6 & 16,8 \\
\hline & 50 & 29,1 & 27,5 & 22,0 & 23,1 & 27,4 & 24,5 \\
\hline & 100 & 51,1 & 52,8 & 50,4 & 42,7 & 51,3 & 46,2 \\
\hline & 150 & 64,3 & 68,2 & 58,2 & 57,5 & 60,3 & 59,2 \\
\hline & & \multicolumn{3}{|c|}{ Crotalária-milho } & \multicolumn{3}{|c|}{ Milheto-milho } \\
\hline & & $2001 / 02$ & & $2002 / 03$ & $2001 / 02$ & & $2002 / 03$ \\
\hline & & \multicolumn{6}{|c|}{ QNPPAV } \\
\hline 0 & 0 & 21,8 & & 20,3 & 2,4 & & 4,6 \\
\hline 30 & 0 & 22,3 & & 25,2 & 3,5 & & 5,9 \\
\hline 30 & 50 & 27,4 & & 24,3 & 3,4 & & 6,7 \\
\hline 30 & 100 & 31,2 & & 35,8 & 3,5 & & 7,6 \\
\hline 30 & 150 & 29,1 & & 34,9 & 4,0 & & 7,4 \\
\hline
\end{tabular}

Verifica-se, no quadro 3, que, de maneira geral, a QNPNS (palha + grãos) foi mais do que o dobro da quantidade proveniente do fertilizante inorgânico e muito superior àquela suprida pelos adubos verdes (Quadro 2), principalmente pelo milheto, sendo esta, na maioria dos tratamentos, superior a $100 \mathrm{~kg} \mathrm{ha}^{-1}$ de N. No primeiro ano agrícola, não houve diferença significativa na QNPNS entre os três sistemas de cobertura do solo utilizados. Já no segundo ano agrícola, foi menor para o milho cultivado em sucessão ao milheto, porém, em média, a diferença foi inferior a $15 \mathrm{~kg} \mathrm{ha}^{-1}$ de N. No entanto, considerando a quantidade média total de $\mathrm{N}$ acumulada no milho $(\mathrm{QNPPF}+\mathrm{QNPPAV}+\mathrm{QNPNS})$ que foi de 183, $158 \mathrm{e}$ $150 \mathrm{~kg} \mathrm{ha}^{-1}$ de $\mathrm{N}$, respectivamente, para o milho cultivado em sucessão à crotalária, pousio e milheto no ano agrícola 2001/02, e de 202, 164 e $148 \mathrm{~kg} \mathrm{ha}^{-1}$ de $\mathrm{N}$, respectivamente, no ano agrícola 2002/03, verifica-se que o milho cultivado em sucessão ao milheto acumulou, respectivamente, nos anos agrícolas 2001/02 e 2002/03, 33 e $52 \mathrm{~kg} \mathrm{ha}^{-1}$ de $\mathrm{N}$ a menos do que o milho cultivado em sucessão à crotalária. Isto demonstra que, considerando a menor produtividade de grãos, o milho cultivado em sucessão 
Quadro 3. Quantidade de nitrogênio nativo do solo no milho (palha, grãos e palha + grãos) (QNPNS) cultivado em sucessão à crotalária, ao milheto e ao solo em pousio, anos agrícolas 2001/02 e 2002/03

\begin{tabular}{lccc}
\hline \multirow{2}{*}{ Sistema de cobertura } & \multicolumn{2}{c}{ QNPNS } & Palha + grão \\
\cline { 2 - 3 } & Grão & Palha & \\
\cline { 2 - 3 } & & Ang ha ${ }^{-1}$ & $102,92 \mathrm{a}$ \\
Crotalária & $70,24 \mathrm{a}^{(1)}$ & $32,68 \mathrm{~b}$ & $106,93 \mathrm{a}$ \\
Pousio & $70,93 \mathrm{a}$ & $36,00 \mathrm{ab}$ & $103,84 \mathrm{a}$ \\
Milheto & $66,88 \mathrm{a}$ & $37,76 \mathrm{a}$ & $119,40 \mathrm{a}$ \\
& & Ano agrícola $2002 / 03$ & $116,49 \mathrm{a}$ \\
Crotalária & $77,02 \mathrm{a}$ & $42,38 \mathrm{a}$ & $106,21 \mathrm{~b}$
\end{tabular}

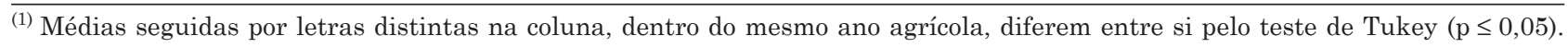

ao milheto acumulou proporcionalmente maior quantidade de $\mathrm{N}$ nativo do solo do que o milho em sucessão à crotalária.

Contudo, apesar da maior percentagem de N nativo do solo acumulada no milho cultivado em sucessão ao milheto (QNPNS/NA x 10²), comparada à do milho em sucessão à crotalária, o $\mathrm{N}$ nativo do solo não contrabalançou o $\mathrm{N}$ suprido pelo fertilizante, em termos de produtividade de grãos, a qual foi menor nessa sucessão. Tal fato, provavelmente, deveu-se à maior relação $\mathrm{C} / \mathrm{N}$ dos resíduos desta gramínea que promoveu maior imobilização do $\mathrm{N}$ mineral presente na solução do solo. Assim, a maior absorção do N nativo do solo pode ter ocorrido numa época em que a planta já tivesse definido sua produção potencial (estádio de quatro a seis folhas expandidas (Fancelli \& Dourado Neto, 2000)), não proporcionando o mesmo efeito que teria proporcionado se fosse absorvido antes dessa fase. Resultados nesse sentido foram observados em outros estudos (Sá, 1996; Varvel et al., 1997).

A partição média do $\mathrm{N}$ absorvido do solo, independentemente das doses de $\mathrm{N}$ e dos sistemas de cobertura do solo, foi de $36 \%$ na palha e $64 \%$ nos grãos, demonstrando que essa característica é de alta herdabilidade e mais dependente do genótipo do que das condições externas do meio ou da quantidade de $\mathrm{N}$ absorvida. Partição de $\mathrm{N}$ na planta semelhante também foi observada em outros estudos, tanto em plantio direto como convencional (Coelho et al., 1991; Lara Cabezas et al., 2000). Verificou-se que grande parte do $\mathrm{N}$ da crotalária e do milheto (36 \%) absorvido pelo milho foi retornada ao solo por meio dos resíduos culturais, devendo parte ser lentamente remineralizada, em virtude da sua alta relação $\mathrm{C} / \mathrm{N}$, e parte interagir com a matéria orgânica mais estável do solo.

A QNPNS, quando o cultivo foi, em sucessão ao milheto, aumentou de forma quadrática nos dois anos agrícolas, em relação às doses de $\mathrm{N}$ aplicadas (Figura 3). Nas demais sucessões, apesar de não terem se ajustado a nenhum modelo testado, houve uma tendência à deflexão com a menor dose de $\mathrm{N}$ aplicada, comparada à do milho em sucessão ao milheto.

A menor QNPNS no cultivo em sucessão à crotalária, considerando sua maior produtividade de grãos e, conseqüentemente, maior quantidade de $\mathrm{N}$ acumulado, além da sua redução com o incremento da dose de $\mathrm{N}$, é um indicativo de que a maior disponibilidade de $\mathrm{N}$ pode ter promovido o maior desenvolvimento do sistema radicular do milho e, ou, maior mineralização dos resíduos da parte aérea da crotalária e, provavelmente, do seu sistema radicular, efeito relatado na literatura como "priming"(Jenkinson et al., 1985). Assim, há favorecimento não só de maior absorção de N, mas também de todos os nutrientes mineralizados concomitantemente dos seus resíduos e dos presentes no solo, com destaque para aqueles que apresentam baixa mobilidade como, por exemplo, o fósforo, que também é um nutriente limitante à produtividade do milho nos solos de cerrado (Novais \& Smith, 1999; Sousa \& Lobato, 2004).

Por outro lado, a menor QNPPF (Quadro 2) e o aumento da QNPNS, mesmo com o incremento da dose de fertilizante nitrogenado no milho cultivado em sucessão ao milheto comparado ao cultivado em sucessão à crotalária, indicam que, nessa sucessão, pode ter predominado o efeito relatado na literatura como "pool substitution", ou seja, o N inorgânico aplicado pode ter tomado o lugar do $\mathrm{N}$ inorgânico nativo do solo que seria imobilizado, deixando, assim, maior quantidade desse nutriente ser absorvido pelas plantas (Jenkinson et al., 1985; Rao et al., 1992; Powlson \& Barraclough, 1993). No entanto, ressalta-se que os processos de interações do $\mathrm{N}$ aplicado ao solo com o $\mathrm{N}$ do solo ocorrem simultaneamente e, na maioria das vezes, são difíceis de ser quantificados em experimentos de campo.

Como para a sucessão pousio-milho não foi considerado o $\mathrm{N}$ proveniente da vegetação espontânea 


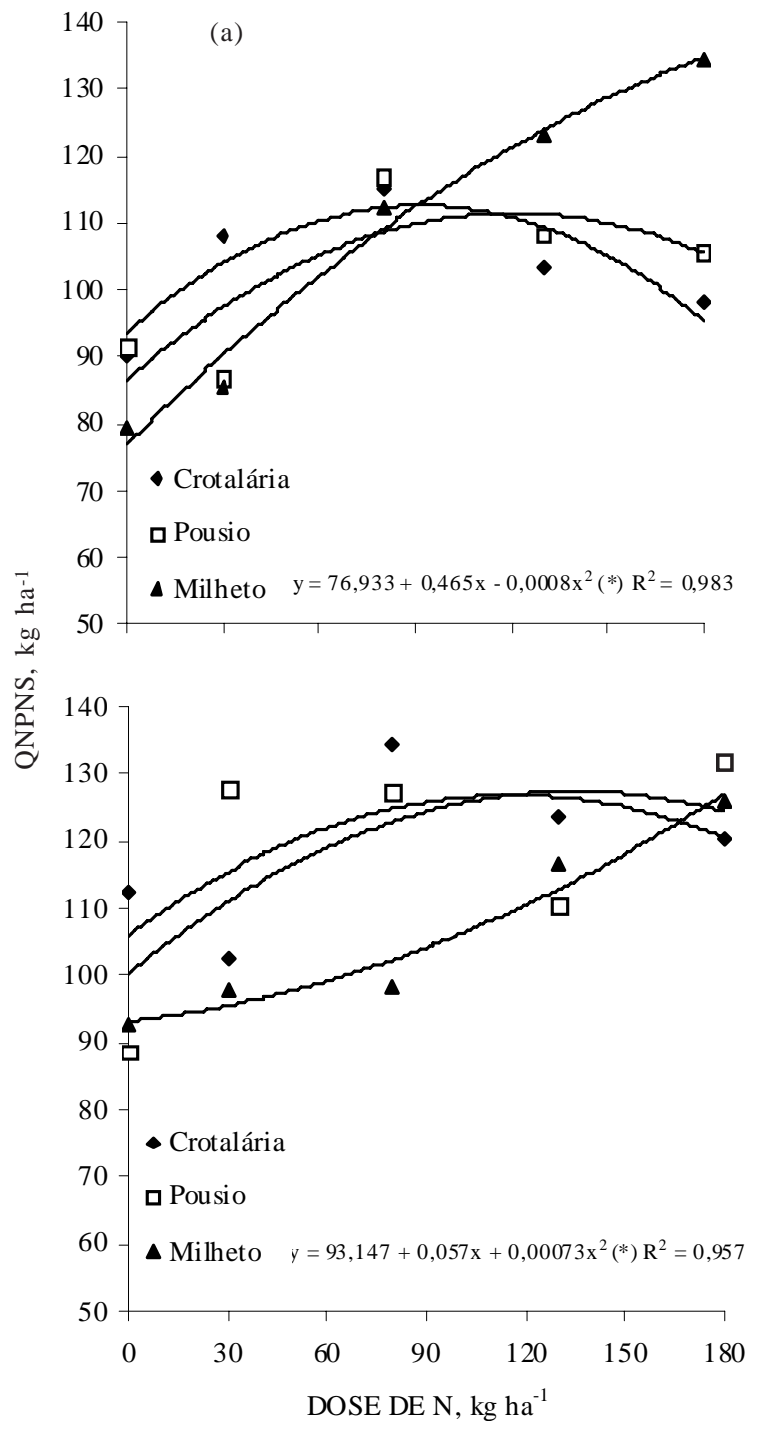

Figura 3. Quantidade de N na planta de milho (palha e grãos) nativo do solo (QNPNS), considerando as doses de $\mathrm{N}$ aplicadas no estádio de quatro ou oito folhas e sistemas de cobertura do solo, anos agrícolas 2001/02 (a) e 2002/03 (b). (* significativo a $5 \%$ pelo teste $\mathrm{F}$ ).

presente na área por ocasião do seu manejo, em virtude de não ter sido ela marcada com ${ }^{15} \mathrm{~N}$, os dados da QNPNS nessa sucessão estão superestimados. Todavia, a recuperação pelo milho do $\mathrm{N}$ dessas plantas não deve ter sido alta, provavelmente, inferior à do $\mathrm{N}$ do milheto, graças à menor quantidade de $\mathrm{N}$ acumulada e à predominância, dentre as plantas daninhas, do capim-colonião, que, assim como o milheto, também apresenta alta relação $\mathrm{C} / \mathrm{N}$, condicionando a uma menor mineralização do $\mathrm{N}$ dessas plantas durante o ciclo do milho comparado à crotalária.

Independentemente da dose de $\mathrm{N}$ ou sistema de cobertura, o solo foi a principal fonte de $\mathrm{N}$ para o milho, sendo superior à uréia conjuntamente aos adubos verdes. Esse resultado diferiu do obtido por Azam et al. (1985) em solo com baixo potencial de fornecimento de N, onde a contribuição das três fontes foi eqüitativa. Já De-Polli \& Chada (1989), estudando a adubação verde incorporada ou em cobertura na produção de milho em solo de baixo potencial de produtividade, verificaram que esta propiciou produtividade até maior que a adubação com $\mathrm{N}$ mineral, proporcionando produtividade até quatro vezes superior à do controle.

Com relação à utilização pelo milho do $\mathrm{N}$ nativo do solo, é importante ressaltar que os valores obtidos neste estudo desconsideram o $\mathrm{N}$ contido no sistema radicular do milho, representando, portanto, uma subestimativa do total recuperado. Possivelmente, esse fato assume maior relevância para o aproveitamento do $\mathrm{N}$ dos adubos verdes, uma vez que existem relatos de que grande parte do $\mathrm{N}$ do adubo verde absorvido pelas plantas de milho fica retida nas raízes (Azam et al., 1985). Pesquisa realizada por Coelho et al. (1991) demonstrou que o sistema radicular do milho representou $5 \%$ da matéria seca total da planta e $4 \%$ do $\mathrm{N}$ total acumulado na planta. Já Lara Cabezas et al. (2000) observaram 10 e $6 \%$, respectivamente, para a matéria seca e $\mathrm{N}$ total.

Apesar do relativo baixo teor de carbono orgânico e de $\mathrm{N}$ total (Figura 1), características comuns dos Latossolos da região de Cerrado (Sousa \& Lobato, 2004), o solo em estudo contribuiu com a maior fração de $\mathrm{N}$ para o milho, provavelmente pela alta labilidade da matéria orgânica particulada, principal forma de acúmulo do carbono orgânico no solo em SPD (Bayer et al., 2004). Resultados semelhantes com elevadas QNPNS em milho foram também verificados em outros estudos em Latossolo Vermelho no Cerrado sob SPD (Lara Cabezas et al., 2004; Figueiredo et al., 2005). Isto evidencia a necessidade de enfatizar sistemas de manejo do solo e do $\mathrm{N}$ que aportem quantidade adequada deste nutriente no cultivo deste cereal, seja na forma orgânica, seja na inorgânica, para a manutenção do potencial produtivo do solo a longo prazo.

\section{CONCLUSÕES}

1. O solo forneceu maior quantidade de $\mathrm{N}$ para o milho, comparada à do fertilizante inorgânico conjuntamente à dos adubos verdes.

2. As doses de $\mathrm{N}$ e os sistemas de cobertura do solo influenciaram significativamente a absorção de $\mathrm{N}$ nativo do solo pelo milho.

3. A absorção de $\mathrm{N}$ nativo do solo pelo milho em sucessão ao milheto aumentou de forma quadrática, considerando as doses de $\mathrm{N}$, e, proporcionalmente, foi maior do que em sucessão à crotalária, que propiciou maior produtividade de grãos. 


\section{AGRADECIMENTOS}

À FAPESP, pela concessão de bolsa de estudo (Processo 01/02427-4); à International Atomic Energy Agency - IAEA, pelo apoio financeiro (Processo BRA. 10954/RB); à UNESP/FEIS, por conceder espaço físico, máquinas e implementos.

\section{LITERATURA CITADA}

AMADO, T.J.C.; MIELNICZUK, J. \& AITA, C. Recomendação de adubação nitrogenada para o milho no RS e SC adaptada ao uso de culturas de cobertura do solo, sob sistema plantio direto. R. Bras. Ci. Solo, 26:241-248, 2002.

AZAM, F.; MALIK, K.A. \& SAJJAD, M.I. Transformations in soil and availability to plants of ${ }^{15} \mathrm{~N}$ applied as inorganic fertilizer and legume residues. Plant Soil, 86:3-13, 1985.

BARRIE, A. \& PROSSER, S.J. Automated analysis of lightelement stable isotopes by isotope ratio mass spectrometry. In: BOUTTON, T.W.\& YAMASAKI, S., eds. Mass spectrometry of soils. New York, Marcel Dekker, 1996. p.1-46.

BAYER, C. \& MIELNICZUK, J. Conteúdo de nitrogênio total num solo submetido a diferentes métodos de preparo e sistemas de cultura. R. Bras. Ci. Solo, 21:235-239, 1997.

BAYER, C.; MARTI-NETO, L.; MIELNICZUK, J. \& PAVINATO, A. Armazenamento de carbono em frações lábeis da matéria orgânica de um Latossolo Vermelho sob plantio direto. Pesq. Agropec. Bras., 39:677-683, 2004.

CALEGARI, A. Alternativa de rotação de culturas para plantio direto. R. Plantio Direto, 80:62-70, 2004.

COELHO, A.M.; FRANÇA, G.C.; BAHIA, A.F.C. \& GUEDES, G.A.A. Balanço de nitrogênio ${ }^{15} \mathrm{~N}$ em Latossolo VermelhoEscuro, sob vegetação de cerrado, cultivado com milho. R. Bras. Ci. Solo, 95:187-193, 1991.

CORAZZA, E.J.; SILVA, J.E.; RESCK, D.V.S. \& GOMES, A.C. Comportamento de diferentes sistemas de manejo como fonte ou depósito de carbono em relação à vegetação de cerrado. R. Bras. Ci. Solo, 23:425-432, 1999.

DE-POLLI, H. \& CHADA, S.S. Adubação verde incorporada ou em cobertura na produção de milho em solo de baixo potencial de produtividade. R. Bras. Ci. Solo, 13:287-293, 1989 .

EMPRESA BRASILEIRA DE PESQUISA AGROPECUÁRIA EMBRAPA. Sistema brasileiro de classificação de solos. Brasília, Serviço de Produção de Informações, 1999. 412p.

FANCELLI, A.L. \& DOURADO NETO, D. Produção de milho. Guaíba, Agropecuária, 2000. 360p.

FERNANDES, L.A.; FURTINI NETO, A.E.; VASCONCELLOS, C.A. \& GUEDES, G.A.A. Preparo do solo e adubação nitrogenada na produtividade do milho em Latossolo sob vegetação de cerrado. R. Bras. Ci. Solo, 22:247-254, 1998.
GONÇALVES, C.N.; CERETTA, C.A. \& BASSO, C.J. Sucessões de culturas com plantas de cobertura e milho em plantio direto e sua influência sobre o nitrogênio do solo. R. Bras. Ci. Solo, 24:153-159, 2000.

FIGUEIREDO, C.C.; RESCK, D.V.S.; GOMES, A.C. \& URQUIAGA, S. Sistemas de manejo na absorção de nitrogênio pelo milho em um Latossolo Vermelho no Cerrado. Pesq. Agropec. Bras., 40:279-287, 2005.

HARRIS, G.H. \& HESTERMAN, O.B. Quantifying the nitrogen contribution from alfafa to soil and two succeeding crops using nitrogen-15. Agron. J., 82:129-134, 1990.

JENKINSON, D.S.; FOX, R.H. \& RAINER, J.H. Interactions between fertilizer nitrogen and soil nitrogen - the socalled priming effect. J. Soil Sci., 36:425-444, 1985.

LARA CABEZAS, W.A.R.; TRIVELIN, P.C.O.; KORNODÔRF, G.H. \& PEREIRA, S. Balanço da adubação nitrogenada sólida e fluida de cobertura na cultura do milho em sistema plantio direto no Triângulo Mineiro. R. Bras. Ci. Solo, 14:363-376, 2000.

LARA CABEZAS, W.R.L.; ALVES, B.J.R.; URQUIAGA, S. \& SANTANA, D.G. Influência da cultura antecessora e da adubação nitrogenada na produtividade de milho em sistema plantio direto e solo preparado. Ci. Rural, 34:10051013, 2004.

MURAOKA, T.; AMBROSANO, E.J.; ZAPATA, F.; BORTOLETTO, N.; MARTINS, A.L.M.; TRIVELIN; P.C.O.; BOARETTO, A.E. \& SCIVITTARO, W.B. Eficiencia de abonos verdes (crotalaria y mucuna) y urea, aplicadas solos o juntamente, como fuentes de $\mathrm{N}$ para el cultivo de arroz. Terra, 20:17-23, 2002.

NOVAIS, R.F. \& SMYTH, T.J. Fósforo em solo e planta em condições tropicais. Viçosa, MG, Universidade Federal de Viçosa, 1999. 399p.

POWLSON, D.S. \& BARRACLOUG, D. Mineralization and assimilation in soil-plant system. In: KNOWLES, R. \& BLACKBURN, T.H., eds. Nitrogen isotope techniques. San Diego, Academic Press, 1993. p.209-242.

RAIJ, B. van; ANDRADE, J.C.; CANTARELLA, H. \& QUAGGIO, J.A. Análise química para avaliação da fertilidade de solos tropicais. Campinas, Instituto Agronômico, 2001. 285p.

RAO, A.C.S.; SMITH, J.L.; PARR, J.F. \& PAPENDICK, R.I. Considerations in estimating nitrogen recovery efficiency by the difference and isotopic dilution methods. Fertil. Res., 33:209-217, 1992.

SÁ, J.C.M. Manejo do nitrogênio na cultura do milho no sistema plantio direto. Passo Fundo, Aldeia Norte, 1996. 24p.

SÁ, J.C.M.; CERRI, C.C.; DICK, A.W.; LAL, R.; VENZKE FILHO, S.P.; PICCOLO, M.C. \& FEIGL, B.E. Soil organic matter dynamics and sequestration rates for a tillage chronosquence in a Brazilian Oxisol. Soil Sci. Soc. Am. J., 65:1476-1499, 2001.

SCIVITTARO, W.B.; MURAOKA, T.; BOARETTO, A.E. \& TRIVELIN, P.C.O. Utilização de nitrogênio de adubos verdes e mineral pelo milho. R. Bras. Ci. Solo, 24:917926, 2000 . 
SCIVITTARO. W.B.; MURAOKA, T.; BOARETTO, A.E. \& TRIVELIN, P.C.O. Transformações do nitrogênio proveniente de mucuna-preta e uréia utilizados como adubo na cultura do milho. Pesq. Agropec. Bras., 38:1427-1433, 2003.

SOUSA, D.M.G. \& LOBATO, E. Adubação com nitrogênio. In: SOUSA, D.M.G. \& LOBATO, E., eds. Cerrado: correção do solo e adubação. 2.ed. Planaltina, Embrapa Cerrados, 2004. p.129-144.
VARVEL, G.E.; SCHPERS, J.S. \& FRANCIS, D.D. Ability for in-season correction of nitrogen deficiency in corn using chlorophyll meters. Soil Sci. Soc. Am. J., 61:1233-1239, 1997.

VITTI, G.C.; FAVARIN, J.L.; REZENDE, L.O. \& TREVISAN, N. Manejo do nitrogênio em diversos sistemas de produção. Piracicaba, Serrana, 1999. 36p. 